University of Wollongong

Research Online

Australian Institute for Innovative Materials -

Papers

Australian Institute for Innovative Materials

$1-1-2019$

Insights into the Electron Transfer Kinetics, Capacitance and Resistance Effects of Implantable Electrodes Using Fourier Transform AC Voltammetry on Platinum

\author{
Alexander R. Harris \\ University of Melbourne, University of Wollongong, alexh@uow.edu.au \\ Carrie Newbold \\ University of Melbourne \\ Robert Cowan \\ University of Melbourne \\ Gordon G. Wallace \\ University of Wollongong, University of Melbourne, gwallace@uow.edu.au
}

Follow this and additional works at: https://ro.uow.edu.au/aiimpapers

Part of the Engineering Commons, and the Physical Sciences and Mathematics Commons

Research Online is the open access institutional repository for the University of Wollongong. For further information contact the UOW Library: research-pubs@uow.edu.au 


\title{
Insights into the Electron Transfer Kinetics, Capacitance and Resistance Effects of Implantable Electrodes Using Fourier Transform AC Voltammetry on Platinum
}

\author{
Abstract \\ The charge transfer mechanism at the electrode-solution interface was assessed by Fourier transform AC \\ voltammetry (FTACV). The faradaic reactions that occur within the safe potential window on platinum had \\ slow electron transfer kinetics. The charge transfer mechanisms during short chronopotentiometric \\ stimulation of cells, is most likely dominated by capacitance. Impedance was modelled with a single time \\ constant. FTACV was fit with a 2-component equivalent circuit comprising a series capacitor and resistor. \\ Capacitance and resistance varied with electrode potential, area, topography, surface functionality and \\ solution composition. Capacitance correlated with charge storage capacity measured by voltammetry. \\ Increased capacitance reduced the change in potential during chronopotentiometry. Increased resistance \\ resulted in uncompensated resistance, and a larger change in potential during chronopotentiometry. \\ Uncompensated resistance in tissue may lead to the measured potential of an electrode being \\ considerably higher than its true potential, leading to a conservative estimate of the safe operating \\ potential window. An impedance test is used to assess electrode performance in vivo. The impedance \\ test is a function of capacitance, faradaic charge and resistance. Impedance test results allow electrode \\ comparison, indicating changes in electrode-tissue interface, electrode failure and power usage, however \\ use of Ohm's law to calculate an impedance value is not valid. \\ Disciplines \\ Engineering | Physical Sciences and Mathematics

\section{Publication Details} \\ Harris, A. R., Newbold, C., Cowan, R. \& Wallace, G. G. (2019). Insights into the Electron Transfer Kinetics, \\ Capacitance and Resistance Effects of Implantable Electrodes Using Fourier Transform AC Voltammetry \\ on Platinum. Journal Of The Electrochemical Society, 166 (12), G131-G140.
}


Insights into the Electron Transfer Kinetics, Capacitance and Resistance Effects of Implantable Electrodes Using Fourier Transform AC Voltammetry on Platinum

Alexander R. Harris ${ }^{1,2}$, Carrie Newbold ${ }^{2,3}$, Robert Cowan ${ }^{2,3}$, Gordon G. Wallace ${ }^{1,2}$

${ }^{1}$ ARC Centre of Excellence for Electromaterials Science, Intelligent Polymer Research Institute, University of Wollongong, Wollongong, NSW, 2522, Australia

${ }^{2}$ The HEARing CRC, 550 Swanston St, University of Melbourne, Melbourne, 3010, Australia

${ }^{3}$ Department of Audiology \& Speech Pathology, 550 Swanston St, University of Melbourne,

Melbourne, 3010, Australia

Email: alexrharris@gmail.com 


\begin{abstract}
The charge transfer mechanism at the electrode-solution interface was assessed by Fourier transform AC voltammetry (FTACV). The Faradaic reactions that occur within the safe potential window on platinum had slow electron transfer kinetics. The charge transfer mechanisms during short chronopotentiometric stimulation of cells, is most likely dominated by capacitance. Impedance was modelled with a single time constant. FTACV was fit with a 2-component equivalent circuit comprising a series capacitor and resistor. Capacitance and resistance varied with electrode potential, area, topography, surface functionality and solution composition. Capacitance correlated with charge storage capacity measured by voltammetry. Increased capacitance reduced the change in potential during chronopotentiometry. Increased resistance resulted in uncompensated resistance, and a larger change in potential during chronopotentiometry. Uncompensated resistance in tissue may lead to the measured potential of an electrode being considerably higher than its true potential, leading to a conservative estimate of the safe operating potential window. An impedance test is used to assess electrode performance in vivo. The impedance test is a function of capacitance, Faradaic charge and resistance. Impedance test results allow electrode comparison, indicating changes in electrode-tissue interface, electrode failure and power usage, however use of Ohm's law to calculate an impedance value is not valid.
\end{abstract}

\title{
Keywords
}

Platinum; Fourier transform AC voltammetry; cochlear implant; capacitance; resistance 


\section{Introduction}

Cells such as neurons and muscle fibres can be sensitive to and produce electrical current. In the case of neurons, changes in local potential can induce an action potential. This action potential can propagate and stimulate further neurons. Large numbers of neurons will form a neural circuit with extensive synaptic connections. These neural circuits enable information processing and integration. For instance, sound waves entering the outer ear are transformed by the inner ear mechanisms into an electrophysiological signal that propagates up the auditorineural pathway to the brain ${ }^{1}$. This pathway serves to process the initial sound waves to provide information on source location, pitch, timbre, intensity and timing, all of which lead to understanding of speech and music.

Trauma and disease can result in the degradation or failure of a neural circuit. In these cases, electrical stimulation via a prosthetic device may be able to bypass the degraded neural circuit. In the case of hearing, overexposure to loud sounds, ototoxic drugs or disease processes such as meningitis are some of the causes of permanent sensorineural hearing loss ${ }^{2}$, which is the direct result of injury or damage to elements of the auditorineural pathway. In some cases, this may be overcome by hearing aids, which amplify certain frequency components of the signal to compensate for reduced acoustic thresholds for these sounds. However, for some of these conditions, which produce a severe-to-profound hearing loss, a cochlear implant may be the only prosthetic option.

The cochlear implant functions by providing access to some of these auditory cues through direct electrical stimulation of the neural elements in the cochlea, rather than the auditory-electrical transformation which happens in normal hearing. The cochlear implant is composed of an array of platinum electrodes embedded in a biocompatible silicone ${ }^{3}$. The electrode array is surgically implanted into the scala tympani within the cochlea. Sound received by an external microphone is converted in an external speech processor into an electrical signal, which is then transmitted across the skin to the implanted receiver-stimulator. The information is then used to stimulate specific auditory neurons though activation of different electrodes along the electrode array. Activation occurs when current is passed through the electrodes to induce activity in nearby auditory neurons.

Under general conditions, the current passed through the electrical circuit is carried by electrons, whereas in tissue, this occurs through the movement of ions. The conversion of electrical to ionic current occurs at the electrode-tissue interface. An important aspect in implanted prosthetics is an understanding of the electrochemical mechanisms occurring at this interface to: ensure that the charge injection is sufficient to induce an action potential, but not great enough to damage local tissue or the electrode; ensure that the electrode surface remains stable and does not deteriorate nor release cytotoxic species into the tissue; and that the injected charge is delivered to the target cells using the minimum necessary voltage to limit power usage. To understand these interfaces and reaction mechanisms, 
studies often assess electrodes in simple saline solutions by cyclic voltammetry, chronopotentiometry or electrochemical impedance spectroscopy (EIS) ${ }^{4}$. It is then inferred that similar mechanisms to those modelled will occur in the complex tissue environments of the human body, and when using the very short, high current density pulsing typically employed in implantable prosthetic devices. However to date, little direct study of the electrochemical reactions occurring at the electrode-tissue interface in cochlear implants has been undertaken.

To understand the electrode-tissue interface, it is important to note that both capacitance and Faradaic reactions may occur. Capacitance charge is caused by the build-up of ions at the electrode-tissue interface. Current flow therefore causes a changing electrode potential across the interface. In contrast, Faradaic reactions involve the movement of electrons across the electrode-tissue interface, resulting in the oxidation or reduction of a redox active species. Charge flow across the interface through Faradaic mechanisms can occur without changing its potential. The charge delivered by Faradaic reactions will depend on the concentration of redox active species at the electrode surface. In the body, redox active species may be dissolved in solution (eg $\mathrm{O}_{2}$ ), so that its concentration at the electrode-tissue interface is affected by mass transport; or adhered to the electrode surface (eg platinum oxide), where mass transport doesn't affect the reaction. There may be a finite amount of redox species present. These surface confined redox reactions can also be called pseudo-capacitance. Redox reactions may be chemically reversible or irreversible.

Charge transfer mechanisms available at a platinum electrode-tissue interface during electrical stimulation are often assumed to be what occurs on a platinum electrode in contact with simple electrolytes such as saline, PBS or $0.5 \mathrm{M} \mathrm{H}_{2} \mathrm{SO}_{4}{ }^{567}$. This includes the formation and reduction of platinum oxide, reduction of molecular oxygen, and the adsorption and stripping of hydride. However, anion adsorption can also occur, with numerous studies showing chloride and phosphate anion adsorption affecting charge transfer at the platinum-electrolyte interface ${ }^{8910}$. These reactions are mostly considered safe, with the reaction products being non-cytotoxic, although the reduction of dissolved oxygen to hydrogen peroxide has been proposed as a possible damage mechanism ${ }^{11}$. However, the charge magnitude obtained from each reaction will depend on the solution composition, electrode surface (area, chemical functionality, crystal plane and topography) and applied waveform. The chemical reversibility of the reactions can also be affected by conditions, for instance the amount of anion adsorption can change over time as the amount of oxide present on the electrode surface changes. Adsorption of amino acids and proteins on the electrode surface may also affect the reaction mechanisms available (eg. blocking anion adsorption or providing other Faradaic reactions) ${ }^{12}$. To accurately predict charge transfer at the electrode-tissue interface therefore requires careful control of the modelled electrode surface and solution composition. 
Other reactions that can occur on the platinum electrode surface include the reduction and oxidation of water and of the electrolyte. These reactions can generate hydrogen and oxygen gas, reactive oxygen species or other reactive products that may be cytotoxic. Stripping of the platinum can also occur, leading to electrode corrosion. The safe potential window is therefore deemed to be the range of electrode potentials that can be applied so that only capacitance and safe Faradaic reactions can occur. The difficulty in defining the safe potential window was recently discussed ${ }^{13}$. The amount of charge that can pass through an electrode within the safe potential window is termed the charge storage capacity or charge injection capacity. The charge storage capacity is typically measured from integrating a DC potential sweep at relatively slow voltammetric scan rates. Dividing this by the electrode area provides its charge density. However, implantable electrodes are normally used in a very short current pulse mode, and the limitations of measuring charge storage capacity from DC cyclic voltammetry was recently discussed ${ }^{1314}$. The charge injection capacity is measured from a chronopotentiometric pulse, being the amount of charge that can be injected before the electrode potential exceeds the safe potential window. The effect of experimental conditions on the charge injection capacity of platinum was also recently reported ${ }^{14}$.

In general, these previous reports assume that all of the reaction mechanisms that occur at the electrodetissue interface are fast. However, Faradaic reactions are also affected by electron transfer kinetics. The electrochemical reactions of some species, such as the oxidation of ferrocene, can have very fast kinetics. Others reactions, including the reduction of protons to molecular hydrogen, can be very slow 15. Reactions that appear to be thermodynamically achievable in a cyclic voltammogram may be limited by slow kinetics and play little role in a short chronopotentiometric pulse.

To gain a greater understanding of the charge transfer mechanisms that may occur at the platinum-tissue interface, we used Fourier transform AC voltammetry (FTACV) ${ }^{16}$. FTACV superimposes an AC signal on a DC cyclic voltammogram, which is equivalent to running multiple cyclic voltammetric scan rates and electrochemical impedance spectroscopy at all applied potentials simultaneously. This technique has been used previously to understand electrochemical mechanisms and kinetics ${ }^{17}$. It has also been used to investigate electrode properties, including screen-printed electrodes developed for point-of-care blood sensing ${ }^{1819}$. In this system, changes in fabrication process and electrode design were found to affect electron transfer rate, electrode capacitance and resistance. The high AC frequencies applied during FTACV may therefore be more relevant in determining the charge transfer mechanisms and charge injection capacity from electrical stimulation of implantable electrodes.

In simple conditions, reaction kinetics can be measured by voltammetry. Fast electron transfer kinetics for a dissolved redox active species undergoing a one-electron redox reaction will produce a DC voltammogram with peaks in the oxidation and reduction sweep separated by $59 \mathrm{mV}$ and the ratio of 
oxidation and reduction current peak heights would be 1. For a surface-confined reaction, the peak separation between oxidation and reduction reactions should be $0 \mathrm{~V}$. As the electron transfer rate decreases, the peak separation will get larger and the peak heights decrease. In AC voltammetry at the fundamental harmonic, fast electron transfer produces a Gaussian shaped peak with no peak splitting from oxidation and reduction sweeps. With slow electron transfer, again the peak heights decrease and peak splitting increases.

The electrochemical performance of implanted electrodes is typically also assessed by EIS which applies an AC signal at a fixed potential. The impedance at $1 \mathrm{kHz}$ is often reported to predict the thermal noise and signal-to-noise ratio of neural recording electrodes. A recent study has demonstrated low frequencies are more dependent on the electrode and are a stronger predictor of electrophysiological performance ${ }^{20}$. Implanted electrodes can also be assessed with an impedance test to determine electrode failure and power usage. The impedance test applies a biphasic chronopotentiometric pulse and uses Ohm's law to calculate a resistance value from the measured potential. Variations of the electrode-solution interface on the impedance test measurement and the validity of this method was recently discussed ${ }^{14}$. Equivalent circuit fitting of FTACV can provide resistance and capacitance measurements, which may be of greater utility to assessing thermal noise, signal-to-noise ratio, electrode failure and power usage of implantable electrodes.

In this article, changes to solution composition, electrode surface area, polishing method (affecting topography and chemical functionality), capacitance and resistance of a platinum electrode were investigated by FTACV. The reaction mechanisms and electron transfer kinetics available on implanted electrodes are discussed. The impact of changing capacitance and resistance on charge injection is investigated. Finally, the relationship between electrochemical methods and fitting of equivalent circuits are discussed in relation to neural stimulation and impedance testing.

\section{Materials and Methods}

\section{Chemicals}

Phosphate-buffered saline (PBS: 154mM NaCl, $10 \mathrm{mM}$ phosphate buffer, $\mathrm{pH}$ 7.4), sodium chloride, potassium chloride, sodium bicarbonate, calcium chloride, D-glucose (Sigma-Aldrich), magnesium chloride hexahydrate (Scharlau), monosodium phosphate (Biochemicals) and $98 \%$ sulfuric acid (RCI Labscan), were used as received. An artificial perilymph contained $125 \mathrm{mM} \mathrm{NaCl}, 3.5 \mathrm{mM} \mathrm{KCl}, 25$ $\mathrm{mM} \mathrm{NaHCO}_{3}, 1.2 \mathrm{mM} \mathrm{MgCl}_{2}, 1.3 \mathrm{mM} \mathrm{CaCl}_{2}, 0.75 \mathrm{mM} \mathrm{NaH}_{2} \mathrm{PO}_{4}$ and $5 \mathrm{mM}$ glucose ${ }^{21}$.

\section{Electrodes}

Electrodes were $2 \mathrm{~mm}, 0.6 \mathrm{~mm}$ or $25 \mu \mathrm{m}$ diameter platinum discs (CH Instruments) or a cochlear implant with 22 half band, $0.3 \mathrm{~mm}^{2}$ nominal area platinum electrodes (donated by Cochlear Ltd). One 
electrode of each type was tested. Disc electrodes were polished before every experiment with $0.3 \mu \mathrm{m}$ alumina slurry on Microcloth polishing cloth (Buehler), rinsed in deionised water and gently dried (Kimwipe) before use. The cochlear implant was not mechanically polished before use and had not been used for any in vivo studies. Acid polishing was achieved by cycling the electrode potential from 1.2 to $-0.2 \mathrm{~V}$ at $50 \mathrm{mV} \mathrm{s}^{-1}$ for 50 cycles in $0.5 \mathrm{M} \mathrm{H}_{2} \mathrm{SO}_{4}$. Electrodes were tested in a 3-electrode configuration using a $\mathrm{Ag} / \mathrm{AgCl}(3 \mathrm{M} \mathrm{KCl})$ as reference electrode and $\mathrm{Pt}$ wire as counter electrode. Unless indicated, test solutions were degassed with nitrogen for at least 10 minutes.

\section{Potentiostats}

DC voltammetry, chronopotentiometry and electrochemical impedance spectroscopy (EIS) experiments were performed on a CHI660E potentiostat (CH Instruments) whereas FTACV was performed on a custom built potentiostat ${ }^{16}$. The electrodes were connected to the potentiostat via alligator clips and placed into a beaker of solution. To increase the electrode capacitance, two $0.3 \mathrm{~mm}^{2}$ platinum disc electrodes were connected in parallel via alligator clips. To increase the electrode resistance, a resistor was placed in series with a $0.3 \mathrm{~mm}^{2}$ platinum electrode via alligator clips.

\section{Applied Waveforms and Analysis}

To perform FTACV, a linear DC sweep from 0.8 to -0.8 and back to $0.8 \mathrm{~V}$ at $119.21 \mathrm{mV} \mathrm{s}^{-1}$ was applied with five $\mathrm{AC}$ frequencies superimposed (37.22, 92.54, 230.07, 372.98 and $590.09 \mathrm{~Hz}$ ) with $5 \mathrm{mV}$ amplitude (Figure S1a). These particular frequencies are chosen to minimise overlap in higher harmonics, frequency sums and differences, although the use of small amplitude AC signals reduces the power of these higher harmonics ${ }^{18}$. A Fourier transform was applied to obtain the power spectrum (Figure S1c), the frequency range of interest was selected with a bandwidth of $18 \mathrm{~Hz}$, and an inverse Fourier transform was applied (Figure S1d and e). A line was then drawn over the top of the current to provide a current envelope (Figure S1f). The magnitude and phase angle were calculated over time and used to calculate a 2-component series resistance $(R)$ and capacitance $(C)$ equivalent circuit from regions that didn't include significant Faradaic current (platinum oxide formation and removal would still be included) or ringing artefacts at the start and end of the potential sweep. The median $R$ and $C$ values were measured over the entire potential range and averaged from 2 repetitions of freshly prepared electrodes.

EIS was performed at $0 \mathrm{~V}$ with an AC amplitude of $5 \mathrm{mV}$ over a frequency range of $0.1-100,000 \mathrm{~Hz}$. Equivalent circuit fitting of the EIS data was performed with ZView (Scribner Associates).

Chronopotentiometic experiments were performed with a biphasic oxidation and reduction waveform of equal pulse length and magnitude but no interphase gap or interpulse interval. 4 biphasic pulses were applied. The charge density was $10 \mu \mathrm{C} \mathrm{cm}^{-2}$, a value typical of that used by modern cochlear implants. 
The cochlear implant typically uses $25 \mu$ s current pulses, however the shortest pulse achievable on the commercial potentiostat was $5 \mathrm{~ms}$. Therefore the applied charge $(Q)$ was calculated by multiplying the charge density by the nominal electrode area $(A)$; the current $(i)$ for the $5 \mathrm{~ms}$ time pulse was then calculated from the total charge passed and the time $(t), i=Q / t ;(5.65 \mu \mathrm{A}$ on a $600 \mu \mathrm{m}$ diameter electrode resulting in $28.3 \mathrm{nC}$ phase $^{-1}$ ). This charge density and charge per phase is considered safe according to the Shannon plot ${ }^{22}$. The current was adjusted to ensure the same charge density of $10 \mu \mathrm{C}$ $\mathrm{cm}^{-2}$ was applied for each electrode size. By definition, the larger the change in potential measured during the chronopotentiometric pulse, the smaller is the electrode's charge injection capacity. To eliminate variability from the open circuit potential, the change in potential from the second pulse was measured (Figure 9a). The stability of the electrode to multiple pulsing was assessed by measuring the change in potential from the end of the second pulse to the end of the last pulse (cumulative 6 pulses).

\section{Results}

\section{Fourier Transform AC Voltammetry}

The applied waveform in FTACV appears like a normal cyclic voltammogram but with a $5 \mathrm{mV}$ amplitude (Figure S1a). The measured total current appears noisy and is more easily visualised when plotted as current versus time (See Figure S1b for a representative example). The Fourier transform of the total current produces a power spectrum with a large component around $0 \mathrm{~Hz}$ associated with the DC sweep and peaks at each of the applied AC frequencies (Figure S1c). No peaks were seen at any other frequencies due to generation of higher harmonics. Selecting only the DC data and applying an inverse Fourier transform generates a typical cyclic voltammogram (Figure S1d). The large current spike at the start and end of the sweep (at $0.8 \mathrm{~V}$ ) is an artefact of the Fourier transform function. An inverse Fourier transform of an AC component produces a mirrored image that is easiest viewed as a current-time plot, seen in Figure 1e for the $37.22 \mathrm{~Hz}$ component of the applied signal. The current envelope is then plotted when viewing multiple plots simultaneously (Figure S1f).

The magnitude and phase angle of each AC component were calculated over time (a typical result is seen in Figure S2). A simple 2-component $R C$ equivalent circuit was then used to compare electrodes under different conditions (Table 1). Both $R$ and $C$ varied with applied potential (Figure 1). Variations in capacitance may be due to changes to the electrode chemical functionality or double layer. Variations in resistance imply the 2-component equivalent circuit is not strictly valid, which will be further discussed below. For a mechanically polished $0.6 \mathrm{~mm}$ diameter platinum electrode in degassed $0.1 \mathrm{M}$ $\mathrm{NaCl}$, the resistance varied over the potential window from 3.1 to $5.2 \mathrm{kOhm}$ while the capacitance varied from 70 to $105 \mathrm{nF}$. A capacitance of $85 \mathrm{nF}$ on a $0.3 \mathrm{~mm}^{2}$ electrode gives a unit capacitance of $28.3 \mu \mathrm{F} \mathrm{cm}^{-2}$.

\section{Varying Solution Composition}


A mechanically polished platinum electrode in degassed $0.1 \mathrm{M} \mathrm{NaCl}$ displays capacitance and Faradaic current (Figure S1d). In the DC sweep, a reduction peak at $-120 \mathrm{mV}$ was seen due to platinum oxide and oxygen reduction; an increasing reduction current below $-500 \mathrm{mV}$ was due to hydride adsorption; on reversing the potential sweep direction, an oxidation current occurred up to $-300 \mathrm{mV}$ from hydride stripping; further oxidation current began at $300 \mathrm{mV}$ from platinum oxide formation. At potentials above $0.8 \mathrm{~V}$ and below $-0.8 \mathrm{~V}$, water electrolysis can occur.

In the $37.22 \mathrm{~Hz} \mathrm{AC}$ reduction sweep, a peak was seen at $-120 \mathrm{mV}$ and the current increased below -500 $\mathrm{mV}$ (Figure S1f and 2b). On the oxidation sweep, the current crossed-over itself at $-650 \mathrm{mV}$, then decreased at $-300 \mathrm{mV}$. A small current peak was also seen at $-20 \mathrm{mV}$. At higher frequencies the current magnitude increased and the peaks became more resolved but didn't change in potential (Figure S1f).

In PBS, the DC voltammetry had a reduction peak at $-10 \mathrm{mV}$, and a large reduction current began around $-400 \mathrm{mV}$ with a shoulder around $-700 \mathrm{mV}$ (Figure 2a). On the oxidation sweep a peak appeared at $-620 \mathrm{mV}$, decreasing in magnitude to $-290 \mathrm{mV}$. Further oxidation current began around $260 \mathrm{mV}$. In the $37.22 \mathrm{~Hz}$ AC reduction sweep a peak occurred at $-600 \mathrm{mV}$ and on the oxidation sweep a larger peak was seen at $-575 \mathrm{mV}$ (Figure $2 \mathrm{~b}$ ). At higher frequencies, a smaller oxidation peak appeared at $-40 \mathrm{mV}$.

An artificial perilymph was also assessed (Figure 2) with the DC voltammetry displaying a reduction peak around $-100 \mathrm{mV}$ and larger reduction process beginning at $-470 \mathrm{mV}$ with a shoulder at $-670 \mathrm{mV}$. The oxidation sweep had a peak at $-700 \mathrm{mV}$ decreasing in magnitude to $-300 \mathrm{mV}$ and a further oxidation process beginning at $120 \mathrm{mV}$. The $37.22 \mathrm{~Hz}$ AC reduction sweep had a peak at $-710 \mathrm{mV}$. On the oxidation sweep the current crossed-over itself at $-590 \mathrm{mV}$, decreasing in current to $-300 \mathrm{mV}$. A small peak was also visible at $260 \mathrm{mV}$. At higher frequencies, oxidation peaks appear at $-410 \mathrm{mV}$ and -65 $\mathrm{mV}$.

FTACV performed in a non-degassed $0.1 \mathrm{M} \mathrm{NaCl}$ solution displayed a larger reduction current at -190 $\mathrm{mV}$ in the DC voltammetry than in a degassed solution (data not shown). The AC components had poorly defined peaks in the reduction sweep around $-200 \mathrm{mV}$ and in the oxidation sweep at $0 \mathrm{~V}$. The Faradaic processes became more resolved at higher AC frequencies.

The median resistance values varied slightly between experiments, ranging from 2.6 to $4.2 \mathrm{kOhm}$ in the different solutions (Table 1). The median capacitance was seen to increase when altering the solution composition from $85 \mathrm{nF}$ in degassed $0.1 \mathrm{M} \mathrm{NaCl}$ up to $116 \mathrm{nF}$ in non-degassed $0.1 \mathrm{M} \mathrm{NaCl}$.

\section{Varying Electrode Surface}


The electrode size was varied in degassed $0.1 \mathrm{M} \mathrm{NaCl}$ (data not shown). The current magnitude in both DC and AC voltammograms increased with electrode size, but the peak potentials were highly consistent. There was a large increase in capacitance and decrease in resistance when increasing the electrode size (Table 1).

All of the electrodes tested above were mechanically polished, resulting in a heterogeneous surface with varying levels of oxide and some organic residues present. Acid cleaning of the electrode leads to a restructuring of the platinum and removal of the impurities. When this acid polished electrode was placed into degassed 0.1 M NaCl, a significant change in voltammetric response was seen (Figure 3). The DC voltammogram displayed reduction peaks at $180 \mathrm{mV}$ and $-350 \mathrm{mV}$ with hydride reduction beginning at $-700 \mathrm{mV}$. On the oxidation sweep, a peak could be seen at $-260 \mathrm{mV}$ with shoulders around $-350 \mathrm{mV}$ and $-200 \mathrm{mV}$. In the $37.22 \mathrm{~Hz} \mathrm{AC}$ reduction sweep, a peak appeared at $-220 \mathrm{mV}$ with increasing current below $-700 \mathrm{mV}$. On the oxidation sweep, peaks were found at $-240 \mathrm{mV}$ and -190 $\mathrm{mV}$. At higher frequencies, further Faradaic processes became visible at 300,30 and $-310 \mathrm{mV}$ on the reduction sweep, and $-630,-470$ and $40 \mathrm{mV}$ on the oxidation sweep. Fitting the 2-component equivalent circuit to the acid polished electrode indicated a near fourfold increase in capacitance with very little change in resistance compared to a mechanically polished electrode (Table 1).

FTACV of a cochlear implant electrode had a similar magnitude of capacitive current as an equivalent sized planar disc electrode, but the Faradaic current was less prominent in both DC and AC voltammograms (Figure 4). The median capacitance averaged from 5 electrodes was slightly smaller than an equivalent sized planar disc electrode while the resistance value was slightly larger (Table 1).

\section{Varying Capacitance and Resistance}

The above experiments altered the platinum-solution interface, resulting in changes to the capacitance and resistance of an equivalent circuit. An increase in electrode capacitance can also be achieved by connecting 2 electrodes in parallel. While an increase in resistance can be made by placing a resistor in series with the electrode.

Increased electrode capacitance resulted in a larger current magnitude in both DC and AC voltammetry with no change in potential of the Faradaic processes (Figure 5a-b). The fitted capacitance increased and the resistance decreased, consistent with a larger electrode area (Table 1).

When increasing the resistance, the DC voltammetry appears stretched out, with Faradaic peak heights decreasing and shifting to larger potentials (Figure 5c). In the AC voltammetry, increasing resistance reduces the current magnitude, and above $67 \mathrm{kOhm}$, the current appears almost independent of applied potential (Figure 5d). With up to $145 \mathrm{kOhm}$ added, the fitted resistance increased while capacitance 
varied slightly; with an added $982 \mathrm{kOhm}$, the fitted capacitance dropped significantly (Table 1). There was very good agreement between the fitted $R$ and the added resistor values.

To obtain a more accurate equivalent circuit, EIS was performed (Figure 6). The Nyquist plot displayed a semi-circle, with increased capacitance reducing the semi-circle height while increased resistance shifted the semi-circle to higher real impedance. The total impedance decreased in magnitude with increasing frequency. Increased capacitance reduced the total impedance at all frequencies while increased resistance increased the total impedance at high frequencies. The phase angle was close to $0^{\circ}$ at high and low frequencies, and approached a $-90^{\circ}$ peak at intermediate frequencies. Increased capacitance broadened the frequency range at $-70^{\circ}$ while increased resistance reduced the range and peak height.

The presence of a semi-circle in the Nyquist plot indicates the electrode-solution interface behaves as a single time constant, which is not generated in a simple $R C$ equivalent circuit. An equivalent circuit (inset Figure 6) consisting of a solution resistance in series with a constant phase element and a parallel polarisation resistance gave a good fit, decreasing in quality with added resistance. Values for the fitted solution and polarisation resistance and an admittance $\left(Q_{0}\right)$ and power $(n)$ term for the constant phase element are given in Table 2. Increasing the electrode capacitance was seen to increase the admittance and reduce the resistance values. The added resistors increased the fitted resistance values with only a small impact on the constant phase element parameters. Despite the simple $R C$ model used to fit the FTACV not being a strictly accurate equivalent circuit of the platinum-solution interface, comparison between the fitted parameters in Tables 1 and 2 indicate a reasonable correlation between $R$, the solution resistance values and the resistor values measured via a multimeter; $C$ also correlated with the admittance values.

Finally, the impact of capacitance and resistance on chronopotentiometry was investigated (Figure 7). At time $=0$, the electrode is at open circuit potential, there was some variability in the initial potential due to differences in the electrode surface after polishing. An initial reduction pulse drives the electrode to negative potentials while an oxidation pulse leads to more positive potentials. The impact of changing the electrode-solution interface and pulse waveform on current pulsing was discussed previously ${ }^{14}$. Increasing the electrode capacitance resulted in a smaller change in potential on the second pulse and for the cumulative 6 pulses (Table 3). Increasing the electrode resistance increased the open circuit potential and the change in potential on the second pulse. However, the change in potential from the cumulative 6 pulses was only affected at large resistances.

\section{Discussion}

General Considerations of Charge Transfer Mechanisms at the Electrode-Tissue Interface 
The reaction mechanisms and charge injection capacity of implantable electrodes are typically measured via slow scan rate voltammetry at relatively low charge densities. Under these conditions, the diffusion length $(L)$ is on the order of $1 \mu \mathrm{m}(L=\sqrt{2 D t}$, where $D$ is the diffusion factor). In contrast, electrical stimulation in vivo is performed with short current pulses at high charge density. The diffusion length may then be 2 or 3 orders of magnitude smaller. This reduces the amount of charge that can be obtained from diffusion of redox species (reduction of oxygen) to the electrode.

Most of the safe electrochemical reactions available at the platinum-solution interface are surface confined. Fast electron transfer should result in Gaussian shaped peaks in both the DC and AC voltammetry. Hydride and anion adsorption approached this behaviour under certain conditions, but the formation and reduction of platinum oxide showed very broad peaks with large splitting in the DC voltammetry and was barely visible in the AC voltammetry (Figures S1, 2-4). The slow kinetics of platinum oxide formation and reduction has been reported previously under a range of conditions ${ }^{2324}$. Acid polishing the electrode may increase the electron transfer kinetics (Figure 3), but this electrode surface is a poor model of the electrode-tissue interface. This implies that the electron transfer kinetics of the platinum oxide reaction is slower than the hydride and anion adsorption, but none of these reactions can be considered fully reversible under these conditions.

Slow electron transfer of the surface confined redox reactions will limit the charge delivered through these mechanisms during short chronopotentiometric pulsing. An electrochemical reaction with slow kinetics can only be forced to proceed by the application of a very high overpotential. The implication is that the majority of charge delivered during in vivo electrical stimulation will be supplied by the electrode's capacitance. Efforts to increase the charge storage capacity of implantable electrodes through relatively slow and quasi-reversible Faradaic reactions from new electrode materials, such as conducting polymers ${ }^{25}$, may have limited benefit in increasing the charge injection capacity for in vivo electrical stimulation. However, quantifying the relative amount of capacitance and each Faradaic reaction mechanism occurring during chronopotentiometry is difficult ${ }^{14}$.

\section{Equivalent Circuits of the Electrode-Tissue Interface}

Electrochemical cells can be modelled as an equivalent electrical circuit. These can aid in understanding the charge transfer mechanisms occurring under different conditions. EIS of platinum in degassed solution at $0 \mathrm{~V}$ vs $\mathrm{Ag} / \mathrm{AgCl}$ displayed a single time constant (Figure 6). An equivalent circuit was fitted with a solution resistance; and the interface between the electrode and electrolyte solution double layer being modelled as a parallel constant phase element and polarisation resistance. The use of a constant phase element rather than a capacitor is usually explained as surface roughness, inhomogeneity in current distribution or inhomogeneity in the surface including ion adsorption ${ }^{26}$. 
Changes in electrode area and solution composition can affect the constant phase element and solution resistance values while modifying the electrode surface should mainly affect the constant phase element.

To gain an accurate understanding of EIS in an electrochemical cell, it should be performed across a range of different electrode potentials. By only performing EIS at one potential, the equivalent circuit doesn't contain charge transfer information for many possible Faradaic reactions or variations in capacitance with potential. In contrast, FTACV is able to provide equivalent circuit parameters at all applied potentials. While the current homebuilt instrument only allows a 2-component equivalent circuit, its accuracy was relatively good under the conditions tested and it allows easy comparison of different electrode and solution conditions (Tables 1 and 2). The fitted capacitance and resistance varied with potential (Figure 1). Variations in capacitance during FTACV have been shown previously with ionic liquid on gold electrode ${ }^{27}$ or of a glassy carbon electrode in $0.2 \mathrm{M} \mathrm{KCl}^{18}$. In these systems, a Ushaped response was seen. The potential dependence of capacitance can then enable measurement of the point of zero charge of the electrode-solution interface. Different shaped responses may indicate specific ion adsorption processes are occurring. The change in measured capacitance with potential in the current work is most likely due to the inclusion of formation and removal of platinum oxide, anion adsorption and changes in the electrical double layer being included in the fitting. The accuracy of the 2-component model after protein fouling and in vivo has not been assessed to date, although an EIS study of protein adsorption on gold electrodes required a second time constant be included to fit the data ${ }^{28}$.

\section{Comparison of Electroanalytical Techniques at the Electrode-Tissue Interface}

A large charge injection capacity should allow delivery of high charge within the safe potential window. A high charge density would allow the electrode area to be reduced, potentially enabling more targeted electrical stimulation and reduction of device size and subsequent immune response.

The impact of experimental conditions on cyclic voltammetry in analysing charge storage capacity and charge density has been discussed recently ${ }^{2913}$. Briefly, the charge storage capacity varies with voltammetric parameters, solution composition, electrode area and surface treatment. The Faradaic reaction mechanisms at a platinum-tissue interface are not fully reversible, and so the charge storage capacity measured from reduction and oxidation sweeps are not equal. The safe potential window is also difficult to define. As a result, charge storage capacity measured via cyclic voltammetry must be performed in a suitable model solution with clinically relevant electrodes using a standardised protocol. The charge density can then be calculated using the geometric or an electrochemically active area, but this must be specified ${ }^{29}$. There is generally a good correlation between charge storage capacity measured by cyclic voltammetry and voltage transients measured by chronopotentiometry ${ }^{14}$. However, 
the stability of an electrode during repeated current pulsing will not be measured from a single cyclic voltammogram.

The impedance at $1 \mathrm{kHz}$ is typically reported to gauge the thermal noise and signal-to-noise ratio of neural recording. However, the utility of this measure in predicting in vivo electrophysiological performance has been mixed ${ }^{30313233}$. A large factor in this poor correlation has been the large biological noise component during in vivo recordings. A novel surgical technique performing multiple neural recording measures from an electrode was able to significantly reduce the biological noise ${ }^{34}$. This enabled correlation of EIS and electrophysiological response ${ }^{20}$. A stronger correlation of impedance at low frequencies (below the Maxwell-Wagner frequency) and electrophysiological behaviour was found than the usually reported impedance at $1 \mathrm{kHz}$. This low frequency impedance is a function of electrode area, indicating larger effective electrode areas will reduce thermal noise and increase the signal-to-noise ratio ${ }^{35}$.

FTACV may be able to provide charge storage capacity and impedance measures in the one experiment. The parameters used in defining FTACV are the potential window, scan rate, number of sine waves, the sine wave amplitude, phase and frequency. A measure of charge storage capacity by integrating an AC voltammogram will be affected by each of these parameters, so they must be standardised. The total current produces oxidation and reduction current during a potential sweep, so that integrating a total current voltammogram would give a very small charge value (Figure S1b). Similarly, integration of the total current from an AC component gives very little charge (Figure S1e). The charge from the DC component and the envelope of the AC components can be obtained (Figure S1d and f). Both of these components provide different charge values for the forward and reverse sweeps and are affected by experimental conditions. As a result, the limitations in measuring charge storage capacity from cyclic voltammetry would be the same with FTACV. In addition, a similar relationship between charge storage capacity measured by FTACV and chronopotentiometry would be expected.

Equivalent circuit fitting of FTACV provided $C$ and $R$ values. While these may not be accurate representations of the electrode-solution interface, they may provide useful measures of charge injection capacity, thermal noise and signal-to-noise ratio. The calculated $C$ and $R$ values varied with potential as the formation and removal of platinum oxide, anion adsorption and changes in the electrical double layer are included in the fitting. Small changes in the potential window and scan rate have little impact on the fitted parameters. As a result, the median values provide an easy measure for comparing different electrodes and conditions. Unlike measures of charge storage capacity, the equivalent circuit fitting should be performed over potential regions without significant Faradaic current. The fitted potential region was kept within the water electrolysis window and excluded the reduction of oxygen, but regions with pseudo-capacitance were included. There was a very good correlation between the $C$ values 
measured in this article and the charge storage capacities reported previously from cyclic voltammetry under the same conditions ${ }^{13}$.

As expected, the fitted $R$ value was mainly affected by electrode area and the addition of resistors to the electrochemical cell. The impact of electrode area was seen to affect the impedance at all measured frequencies while added resistance had a greater impact at higher impedance frequencies (Figure 6).

\section{Capacitance and Resistance Effects During Chronopotentiometry and Impedance Testing at the}

\section{Electrode-Tissue Interface}

Stimulation of excitable cells is normally achieved with biphasic current (chronopotentiometric) pulses. Analysis of chronopotentiometric pulsing of implantable electrodes is often performed by measuring the rapid change in potential occurring in the first few $\mu$ s (access voltage) and the subsequent slower change in potential (polarisation voltage) ${ }^{36}$. This assumes the access voltage is due to the solution resistance and the polarisation voltage is due to a change in potential across the electrode-tissue interface. Separating out each of these phases of a chronopotentiometric pulse can be achieved with a dummy cell, but becomes harder in electrochemical cells.

An impedance test is also used to assess the performance of implants ${ }^{373839}$. The test varies between devices, but typically involves the use of Ohm's law to calculate an impedance value from a biphasic current pulse. The use of Ohm's law requires a uniform conductor; an electrochemical system is not a uniform conductor, as current is supplied by capacitance and/or Faradaic reactions ${ }^{14}$. Therefore, an impedance test can provide details on electrode failure and power usage but only estimates of tissue resistance.

During a chronopotentiometric pulse, when charge is supplied by capacitance, the electrode potential will increase over time, while charge generated from Faradaic reactions will result in a more stable electrode potential. The charge transfer mechanisms and their kinetics depend on the composition of the electrode-tissue interface, electrode area, applied charge density and pulse length ${ }^{14}$. The Faradaic charge transfer mechanisms at the platinum-solution interface are not fully reversible, so using a charge balanced biphasic pulse doesn't guarantee balanced reaction mechanisms. Multiple biphasic pulses can then lead to a change in the electrode-tissue interface (eg. changes to chemical functionality, ion adsorption, electrical double layer) and ratcheting of the electrode potential ${ }^{4041}$.

The change in electrode potential during chronopotentiometry was shown previously to be affected by electrode area, solution composition, electrode surface, current magnitude, pulse length, pulse polarity and number of pulses ${ }^{14}$. Here the capacitance and resistance are also shown to affect the chronopotentiometric response. Increasing the electrode capacitance reduces the change in potential 
while increasing the resistance increases the change in potential. This behaviour can be predicted from the 2-component model fitting with FTACV.

The safe potential window assumes that all current $(i)$ is supplied by capacitance $\left(i_{\mathrm{c}}\right)$ and Faradaic $\left(i_{\mathrm{f}}\right)$ current and that the measured potential $(E)$ is the true potential at the electrode surface. The presence of uncompensated resistance $\left(R_{\mathrm{u}}\right)$ also affects the electrode potential according to $E_{u}=i R_{\mathrm{u}}$. (where $E_{\mathrm{u}}$ is the additional potential measured at the interface due to uncompensated resistance and $E=E_{\mathrm{u}}+E_{\mathrm{t}}$ where $E_{\mathrm{t}}$ is the true potential at the interface) When performing cyclic voltammetry, the presence of $i R_{\mathrm{u}}$ drop will require a larger applied potential to achieve the desired electrode potential. As a result, $i R_{\mathrm{u}}$ drop will shift Faradaic reactions to larger applied potentials and the safe potential window will appear wider. In chronopotentiometry, the applied current is controlled so the measured potential will become larger with added $i R_{\mathrm{u}}$ drop. So while the measured potential may be significantly greater than the safe potential window, the true electrode potential may still be within the safe potential window. The impact of $i R_{\mathrm{u}}$ drop will be noticed when the change in potential is greater than a few $\mathrm{mV}$. For instance, with an applied current of $5.65 \mu \mathrm{A}$, the effects of $i R_{\mathrm{u}}$ drop will be noticeable with resistances above $1 \mathrm{kOhm}$. For shorter current pulses with larger applied current, the effect of $i R_{\mathrm{u}}$ drop will be even greater.

Larger resistance and capacitance also increases the electrode time constant $(R C)$ which leads to a slower change in electrode potential with applied current. The larger time constant can be seen when large resistors were added to the chronopotentiometric pulsing (Figure 7c-d). At very large resistances (demonstrated at $982 \mathrm{kOhm}$ ), parasitic capacitance leads to shunting of charge. These effects of resistance lead to a blurring of the access and polarisation voltages, preventing their separation.

Due to protein fouling and cell encapsulation, the impedance of an electrode in tissue is typically greater than in simple solutions. This will lead to uncompensated resistance effects, which will vary between electrodes and over time. As a result, the safe potential window in vivo may be wider than measured in a highly conductive solution. Chronopotentiometric pulsing would also lead to larger changes in potential. Performing an impedance test in vivo will result in a change in electrode potential with charge being passed through capacitance, Faradaic reactions and uncompensated resistance. The mechanisms involved in charge transfer will change over time due to the electrical stimulation and biological processes such as protein adsorption and fibrosis. Deconvoluting the charge transfer mechanisms in vivo is difficult but it does give an indication of the level of tissue impedance. A reduction in tissue resistivity will reduce the uncompensated resistance and reduce power usage during electrical stimulation. 


\section{Conclusions}

Charge transfer from a platinum electrode into solution occurs through capacitance and Faradaic mechanisms. The Faradaic mechanisms include platinum oxide formation and reduction, anion adsorption, reduction of oxygen and hydride adsorption. These reactions all displayed slow electron transfer on a mechanically polished electrode. Acid polishing of the electrode appeared to increase the reaction kinetics, but this surface is a poor model of the electrode-tissue interface. Therefore, it is expected that slow electron transfer at the platinum-tissue interface would also occur. Capacitance would then dominate the charge transfer mechanisms at the platinum-tissue interface during electrical stimulation of cells. The development of new materials with large charge storage capacities but slow electron transfer may be of limited benefit in increasing the charge injection capacity of neural stimulating electrodes. Increasing the electrode capacitance was found to have a bigger impact in increasing its charge injection capacity.

The electrochemical properties of implantable electrodes are normally assessed in highly conductive electrolytes. Increased resistance leads to uncompensated resistance effects so the true electrode potential may be smaller than the measured potential. The impedance of tissue is larger and more complex than in these highly conductive electrolytes. Therefore, the safe potential window and charge injection capacity available in tissue may be wider than measured in the highly conductive electrolytes. The level of uncompensated resistance may also vary between electrodes and over time. The safe potential window on a cochlear implant may vary across the electrode array and as any fibrotic tissue forms around the electrodes. An impedance test of the cochlear implant electrodes can give an estimate of the level of uncompensated resistance.

The electrophysiological performance of implantable electrodes is often modelled by electrochemical methods in simple electrolytes. A slow sweep DC cyclic voltammogram is used to calculate the charge storage capacity and EIS is used to predict thermal noise and signal-to-noise ratio. FTACV is able to measure a charge storage capacity and impedance response within one experiment. Unlike EIS, FTACV also measures the impedance response over the whole potential range. FTACV may therefore provide more information within a single experiment to better model electrophysiological performance. 


\section{Acknowledgements}

The authors acknowledge the financial support of the HEARing CRC, established under the Australian Government's Cooperative Research Centres (CRC) Program. The CRC Program supports industry-led collaborations between industry, researchers and the community. Funding from the Australian Research Council Centre of Excellence Scheme (Project Number CE140100012) is gratefully acknowledged. The authors thank the Materials Node of Australian National Fabrication Facility (ANFF) and acknowledge use of the facilities.

\section{References}

1. D. R. Moore, P. A. Fuchs, A. Rees, A. Palmer, and C. J. Plack, The Oxford Handbook of Auditory Science: The Auditory Brain, OUP Oxford, (2010).

2. L. R. Lustig, Hear. Res., 368, 3-9 (2018).

3. A. Dhanasingh and C. Jolly, Hear. Res., 356, 93-103 (2017).

4. S. F. Cogan, Annu. Rev. Biomed. Eng., 10, 275-309 (2008).

5. S. B. Brummer and M. J. Turner, Biomed. Eng. IEEE Trans., BME-24, 436-439 (1977).

6. S. B. Brummer and M. J. Turner, Biomed. Eng. IEEE Trans., BME-24, 440-443 (1977).

7. E. M. Hudak, D. W. Kumsa, H. B. Martin, and J. T. Mortimer, J. Neural Eng., 14, 46012 (2017).

8. V. S. Bagotzky, Y. B. Vassilyev, J. Weber, and J. N. Pirtskhalava, J. Electroanal. Chem. Interfacial Electrochem., 27, 31-46 (1970).

9. N. Li and J. Lipkowski, J. Electroanal. Chem., 491, 95-102 (2000).

10. N. Garcia-Araez, V. Climent, E. Herrero, J. Feliu, and J. Lipkowski, J. Electroanal. Chem., 576, 33-41 (2005).

11. S. L. Morton, M. L. Daroux, and J. T. Mortimer, J. Electrochem. Soc., 141, 122-130 (1994).

12. D. B. Hibbert, K. Weitzner, and P. Carter, J. Electrochem. Soc., 148, E1-E7 (2001).

13. A. R. Harris, C. Newbold, P. Carter, R. Cowan, and G. G. Wallace, J. Neural Eng., 15, 46015 (2018).

14. A. R. Harris, C. Newbold, P. Carter, R. Cowan, and G. G. Wallace, Front. Neurosci.

15. A. J. Bard and L. R. Faulkner, Electrochemical Methods, 2nd ed., Wiley, New York, (2001).

16. A. M. Bond, N. Duffy, S. Guo, J. Zhang, and D. Elton, Anal. Chem., 77, 186A-195A (2005).

17. Y. Zhang, A. N. Simonov, J. Zhang, and A. M. Bond, Curr. Opin. Electrochem., 10, 72-81

(2018).

18. A. R. Harris et al., J. Solid State Electrochem., 12 (2008).

19. A. Konash et al., J. Solid State Electrochem., 13 (2009).

20. A. R. Harris, B. J. Allitt, and A. G. Paolini, Anal. (Cambridge, United Kingdom).

21. A. N. Salt, C. Kellner, and S. Hale, Hear. Res., 182, 24-33 (2003).

22. S. F. Cogan, K. A. Ludwig, C. G. Welle, and P. Takmakov, J. Neural Eng., 13, 21001 (2016).

23. S. W. Feldberg, C. G. Enke, and C. E. Bricker, J. Electrochem. Soc. , 110, 826-834 (1963).

24. S. Shibata and M. P. Sumino, Electrochim. Acta, 20, 739-746 (1975).

25. A. R. Harris and G. G. Wallace, Adv. Funct. Mater., 28, 1700587 (2018).

26. T. Pajkossy, J. Electroanal. Chem., 364, 111-125 (1994).

27. A. J. Lucio, S. K. Shaw, J. Zhang, and A. M. Bond, J. Phys. Chem. C, 121, 12136-12147 (2017).

28. T. Sun, W. M. Tsang, W.-T. Park, K. Cheng, and S. Merugu, Microsyst. Technol., 21, 1739-1747 (2015).

29. A. G. Paolini et al., Anal. Chem., 87, 738-746 (2014).

30. P. J. Rousche and R. A. Normann, J. Neurosci. Methods, 82, 1-15 (1998).

31. M. P. Ward, P. Rajdev, C. Ellison, and P. P. Irazoqui, Brain Res., 1282, 183-200 (2009).

32. S. R. Kane et al., Biomed. Eng. IEEE Trans., 60, 2153-2160 (2013).

33. K. H. Chen et al., J. Neural Eng., 11, 26004 (2014).

34. A. R. Harris et al., J. Neural Eng., 10, 016004 (2013).

35. A. R. Harris et al., Analyst, 140, 3164-3174 (2015). 
36. M. Tykocinski, L. T. Cohen, and R. S. Cowan, Otol. Neurotol., 26, 948-956 (2005).

37. C. Newbold and et al., J. Neural Eng., 1, 218 (2004).

38. C. Newbold and et al., J. Neural Eng., 7, 56011 (2010).

39. C. Newbold and et al., J. Neural Eng., 8, 36029 (2011).

40. D. R. Merrill, M. Bikson, and J. G. R. Jefferys, J. Neurosci. Methods, 141, 171-198 (2005).

41. D. W. Kumsa, F. W. Montague, E. M. Hudak, and J. T. Mortimer, J. Neural Eng., 13, 56001 (2016).

Table 1. Median resistance and capacitance measured from an $R C$ equivalent circuit during FTACV on a platinum electrode from different conditions.

\begin{tabular}{|c|c|c|c|c|c|c|c|}
\hline $\begin{array}{c}\text { Tested } \\
\text { Variable }\end{array}$ & $\begin{array}{l}\text { Electrode } \\
\text { Diameter }\end{array}$ & $\begin{array}{l}\text { Polish } \\
\text { Method }\end{array}$ & Solution & Degassed & $\begin{array}{c}\text { Added Resistor } \\
\text { /kOhm }\end{array}$ & $\begin{array}{l}\text { Resistance } \\
\text { /kOhm }\end{array}$ & $\begin{array}{c}\text { Capacitance } \\
/ \mathrm{nF}\end{array}$ \\
\hline \multirow{4}{*}{$\begin{array}{c}\text { Solution } \\
\text { Composition }\end{array}$} & $600 \mu \mathrm{m}$ & Mechanical & $0.1 \mathrm{M} \mathrm{NaCl}$ & Yes & - & 4.2 & 85 \\
\hline & $600 \mu \mathrm{m}$ & Mechanical & PBS & Yes & - & 3.7 & 89 \\
\hline & $600 \mu \mathrm{m}$ & Mechanical & $\begin{array}{l}\text { Artificial } \\
\text { perilymph }\end{array}$ & Yes & - & 2.6 & 110 \\
\hline & $600 \mu \mathrm{m}$ & Mechanical & $0.1 \mathrm{M} \mathrm{NaCl}$ & No & - & 3.2 & 116 \\
\hline \multirow{4}{*}{$\begin{array}{l}\text { Electrode } \\
\text { Surface }\end{array}$} & $2 \mathrm{~mm}$ & Mechanical & $0.1 \mathrm{M} \mathrm{NaCl}$ & Yes & - & 0.42 & 1240 \\
\hline & $25 \mu \mathrm{m}$ & Mechanical & $0.1 \mathrm{M} \mathrm{NaCl}$ & Yes & - & 2600 & 0.18 \\
\hline & $600 \mu \mathrm{m}$ & Acid & $0.1 \mathrm{M} \mathrm{NaCl}$ & Yes & - & 2.9 & 335 \\
\hline & Cochlear Implant & - & $\begin{array}{l}\text { Artificial } \\
\text { perilymph }\end{array}$ & Yes & - & $5.5(1.7) *$ & $81(34) *$ \\
\hline Capacitance & 2 parallel $600 \mu \mathrm{m}$ & Mechanical & $0.1 \mathrm{M} \mathrm{NaCl}$ & Yes & - & 1.3 & 267 \\
\hline \multirow{4}{*}{ Resistance } & $600 \mu \mathrm{m}$ & Mechanical & $0.1 \mathrm{M} \mathrm{NaCl}$ & Yes & 1 & 4.6 & 77 \\
\hline & $600 \mu \mathrm{m}$ & Mechanical & $0.1 \mathrm{M} \mathrm{NaCl}$ & Yes & 67 & 69 & 123 \\
\hline & $600 \mu \mathrm{m}$ & Mechanical & $0.1 \mathrm{M} \mathrm{NaCl}$ & Yes & 145 & 147 & 109 \\
\hline & $600 \mu \mathrm{m}$ & Mechanical & $0.1 \mathrm{M} \mathrm{NaCl}$ & Yes & 982 & 981 & 17 \\
\hline
\end{tabular}

Median resistance and capacitance values measured over entire potential range was averaged from 2 repetitions. *Average (standard deviation) of 5 electrodes.

Table 2. Electrochemical impedance parameters from equivalent circuit fitting in degassed artificial perilymph with varying capacitance and resistance.

\begin{tabular}{|c|c|c|c|c|c|}
\hline Electrode Diameter & $\begin{array}{l}\text { Added Resistor } \\
\text { /kOhm }\end{array}$ & $\begin{array}{l}\text { Solution } \\
\text { Resistance } \\
\text { /Ohm }\end{array}$ & $Q_{0} /{ }_{\mathrm{S}^{1 / 2}}^{10^{-9} \mathrm{~S}}$ & $n$ & $\begin{array}{l}\text { Polarisation } \\
\text { Resistance } \\
\text { /MOhm }\end{array}$ \\
\hline $600 \mu \mathrm{m}$ & - & 957 & 246 & 0.87 & 2.06 \\
\hline 2 parallel $600 \mu \mathrm{m}$ & - & 394 & 445 & 0.87 & 1.17 \\
\hline $600 \mu \mathrm{m}$ & 1 & 1800 & 223 & 0.88 & 1.80 \\
\hline $600 \mu \mathrm{m}$ & 67 & 67400 & 221 & 0.87 & 1.68 \\
\hline $600 \mu \mathrm{m}$ & 145 & 145000 & 189 & 0.87 & 2.30 \\
\hline $600 \mu \mathrm{m}$ & 982 & 911000 & 168 & 0.83 & 4.05 \\
\hline
\end{tabular}


Table 3. Change in potential on a mechanically polished platinum electrode in degassed artificial perilymph after a $5 \mathrm{~ms}$ pulse at $10 \mu \mathrm{C} \mathrm{cm}^{-2}$ with varying capacitance and resistance.

\begin{tabular}{ccccc}
\hline Electrode Diameter & $\begin{array}{c}\text { Initial Applied } \\
\text { Pulse Polarity }\end{array}$ & $\begin{array}{c}\text { Added Resistor } \\
\text { /kOhm }\end{array}$ & \multicolumn{2}{c}{ Change in Potential /mV } \\
\cline { 3 - 5 } & & & Second Pulse & Cumulative 6 Pulses \\
\hline $600 \mu \mathrm{m}$ & Cathodic & - & 269 & 28 \\
$600 \mu \mathrm{m}$ & Anodic & - & -263 & -27 \\
2 parallel $600 \mu \mathrm{m}$ & Cathodic & - & 169 & 10 \\
2 parallel $600 \mu \mathrm{m}$ & Anodic & - & -162 & -16 \\
$600 \mu \mathrm{m}$ & Cathodic & 1 & 293 & 39 \\
$600 \mu \mathrm{m}$ & Anodic & 1 & -297 & -28 \\
$600 \mu \mathrm{m}$ & Cathodic & 67 & 1.01 & 36 \\
$600 \mu \mathrm{m}$ & Anodic & 67 & -1.01 & -29 \\
$600 \mu \mathrm{m}$ & Cathodic & 145 & 1.847 & 34 \\
$600 \mu \mathrm{m}$ & Anodic & 145 & -1.854 & -28 \\
$600 \mu \mathrm{m}$ & Cathodic & 982 & 6.674 & 407 \\
$600 \mu \mathrm{m}$ & Anodic & 982 & -6.655 & -410 \\
\hline
\end{tabular}




\section{Figure Captions}

Figure 1. Resistance and capacitance calculated from a series $R C$ equivalent circuit from FTACV of a mechanically polished $0.6 \mathrm{~mm}$ diameter platinum electrode in degassed $0.1 \mathrm{M} \mathrm{NaCl}$. Applied waveform was a DC sweep from 0.8 to $-0.8 \mathrm{~V}$ at a scan rate of $119.21 \mathrm{mV} \mathrm{s}^{-1}$ with AC components of $37.22,92.54$, 230.07, 372.98 and $590.09 \mathrm{~Hz}$ at $5 \mathrm{mV}$ amplitude.

Figure 2. FTACV of a mechanically polished $0.6 \mathrm{~mm}$ diameter platinum electrode in degassed $0.1 \mathrm{M}$ $\mathrm{NaCl}$, PBS or artificial perilymph. Applied waveform was a DC sweep from 0.8 to $-0.8 \mathrm{~V}$ at a scan rate of $119.21 \mathrm{mV} \mathrm{s}^{-1}$ with $\mathrm{AC}$ components of $37.22,92.54,230.07,372.98$ and $590.09 \mathrm{~Hz}$ at $5 \mathrm{mV}$ amplitude. (a) DC component of the current, (b) envelop of the AC current of the fundamental component at $37.22 \mathrm{~Hz}$.

Figure 3. FTACV of a mechanically or acid polished $0.6 \mathrm{~mm}$ diameter platinum electrode in degassed $0.1 \mathrm{M} \mathrm{NaCl}$. Applied waveform was a DC sweep from 0.8 to $-0.8 \mathrm{~V}$ at a scan rate of $119.21 \mathrm{mV} \mathrm{s}^{-1}$ with AC components of 37.22, 92.54, 230.07, 372.98 and $590.09 \mathrm{~Hz}$ at $5 \mathrm{mV}$ amplitude. (a) DC component of the current, (b) envelop of the AC current of the fundamental component at $37.22 \mathrm{~Hz}$.

Figure 4. FTACV of a mechanically polished $0.6 \mathrm{~mm}$ diameter platinum electrode or cochlear implant electrode in degassed $0.1 \mathrm{M} \mathrm{NaCl}$. Applied waveform was a DC sweep from 0.8 to $-0.8 \mathrm{~V}$ at a scan rate of $119.21 \mathrm{mV} \mathrm{s}^{-1}$ with AC components of 37.22, 92.54, 230.07, 372.98 and $590.09 \mathrm{~Hz}$ at $5 \mathrm{mV}$ amplitude. (a) DC component of the current, (b) envelop of the AC current of the fundamental component at $37.22 \mathrm{~Hz}$.

Figure 5. FTACV of a mechanically polished $0.6 \mathrm{~mm}$ diameter platinum electrode in degassed $0.1 \mathrm{M}$ $\mathrm{NaCl}$. Applied waveform was a DC sweep from 0.8 to $-0.8 \mathrm{~V}$ at a scan rate of $119.21 \mathrm{mV} \mathrm{s}^{-1}$ with AC components of $37.22,92.54,230.07,372.98$ and $590.09 \mathrm{~Hz}$ at $5 \mathrm{mV}$ amplitude. (a-b) increasing capacitance with two $0.6 \mathrm{~mm}$ diameter platinum electrode in parallel (c-d) increased resistance with resistors added in series with the platinum electrode. (a and c) DC component of the current, (b and d) envelop of the AC current of the fundamental component at $37.22 \mathrm{~Hz}$.

Figure 6. Electrochemical impedance of a mechanically polished $0.6 \mathrm{~mm}$ diameter platinum electrode in degassed artificial perilymph at $0 \mathrm{~V}$ with an $\mathrm{AC}$ amplitude of $5 \mathrm{mV}$. (a, c) increasing capacitance with two $0.6 \mathrm{~mm}$ diameter platinum electrode in parallel $(\mathrm{b}, \mathrm{d})$ increased resistance with resistors added in series with the platinum electrode.

Figure 7: Multiple pulse chronopotentiometry of a mechanically polished $0.6 \mathrm{~mm}$ diameter platinum electrode in degassed artificial perilymph. (a, c) Cathodic, $(b, d)$ anodic pulse first with a current density of $10 \mu \mathrm{C} \mathrm{cm}^{-2}$. (a, b) increasing capacitance with two $0.6 \mathrm{~mm}$ diameter platinum electrode in parallel (c, d) increased resistance with resistors added in series with the platinum electrode. 


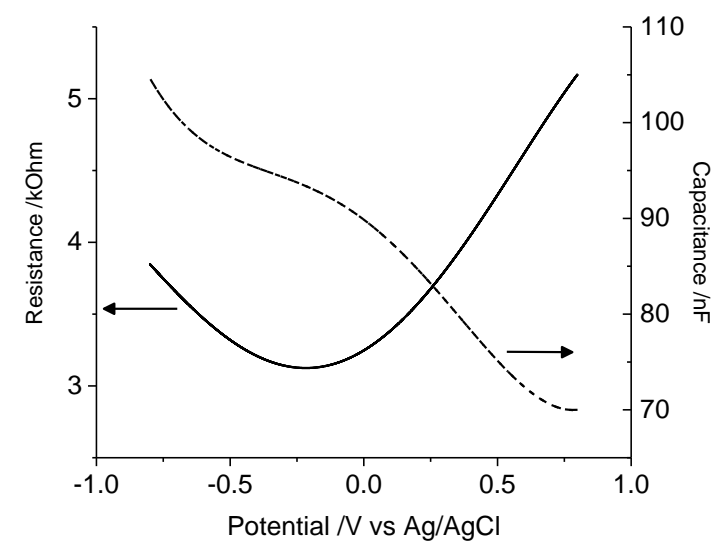

Figure 1

a

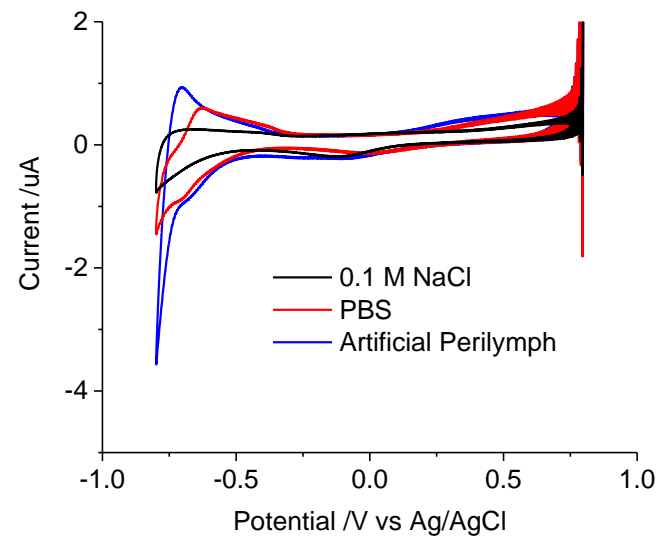

b

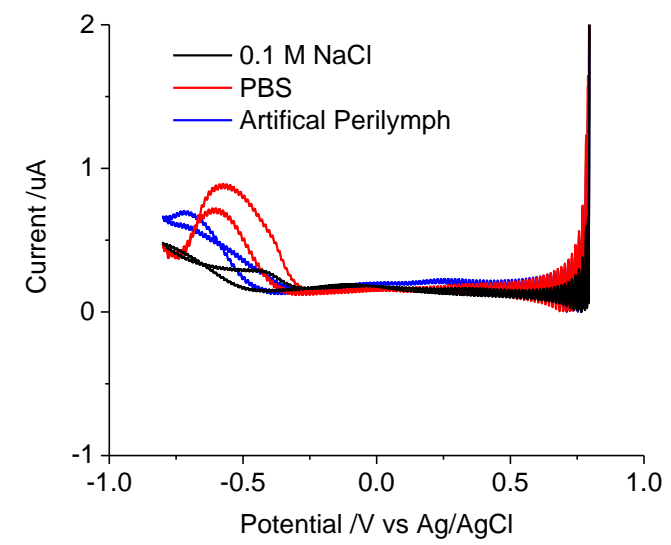

Figure 2

a

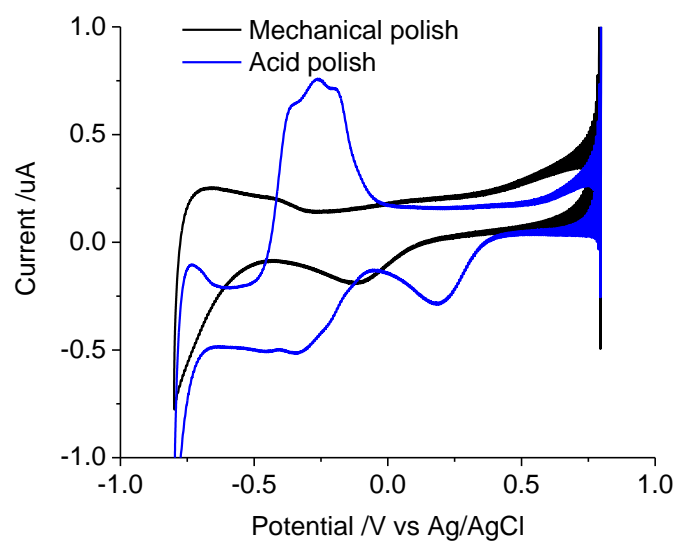

b

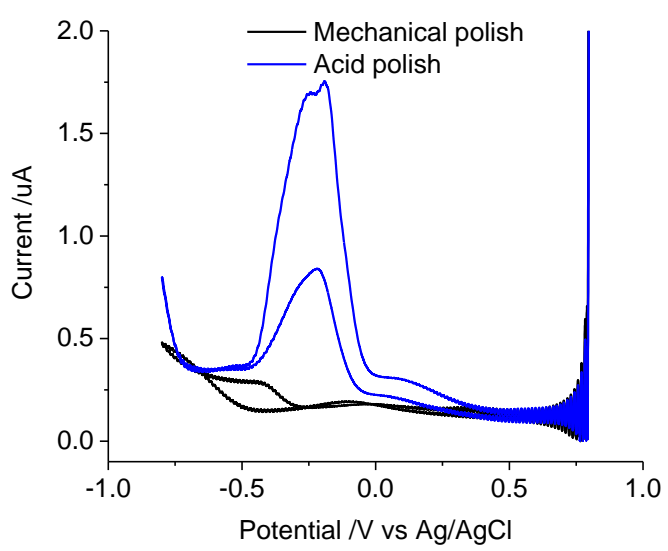

Figure 3 
a

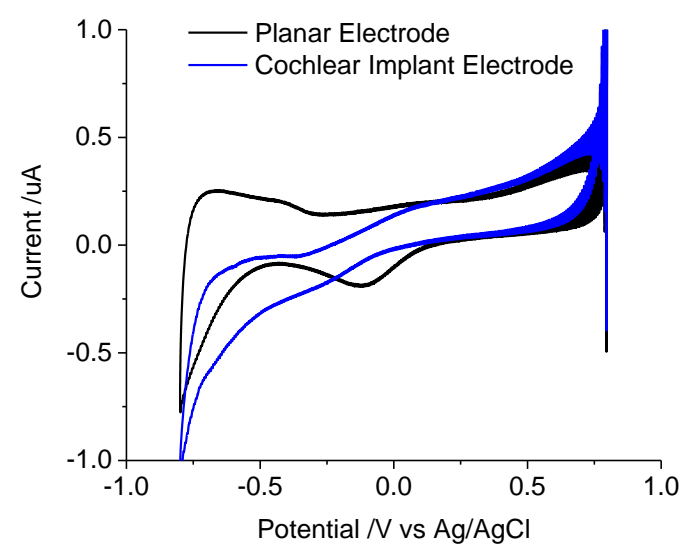

Figure 4

a

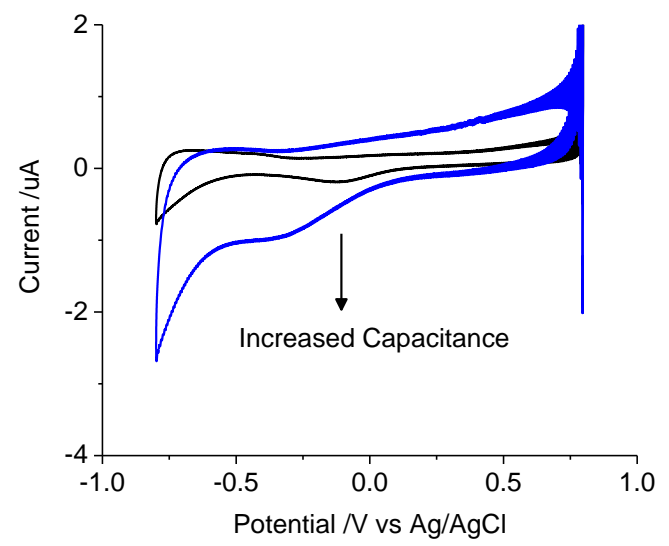

C

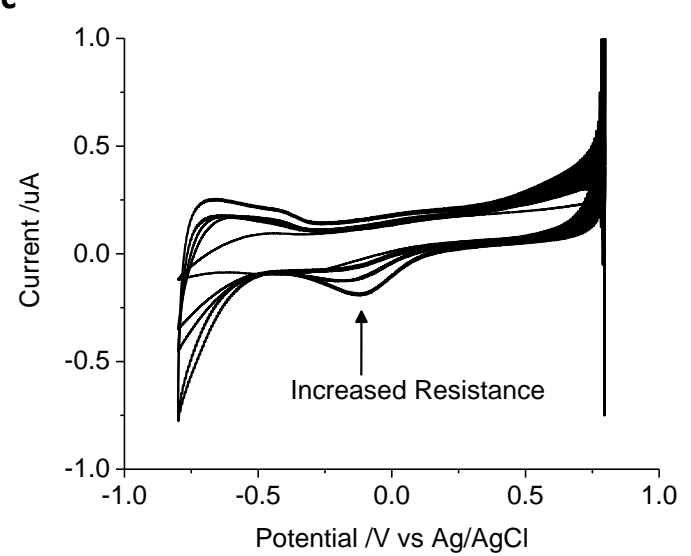

b

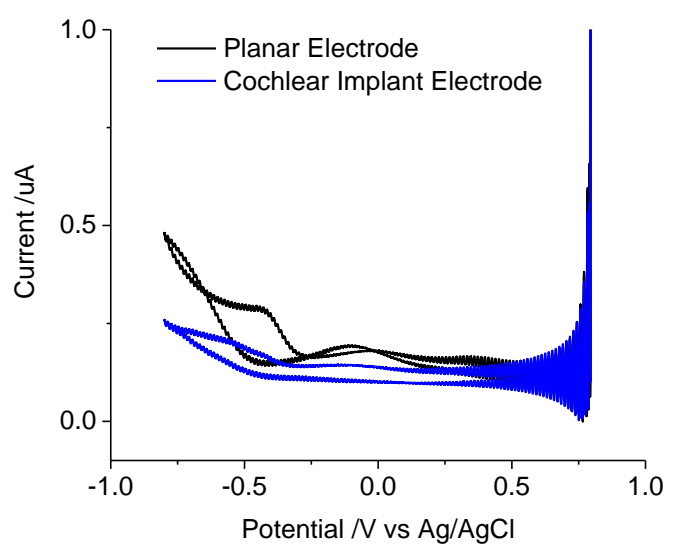

b

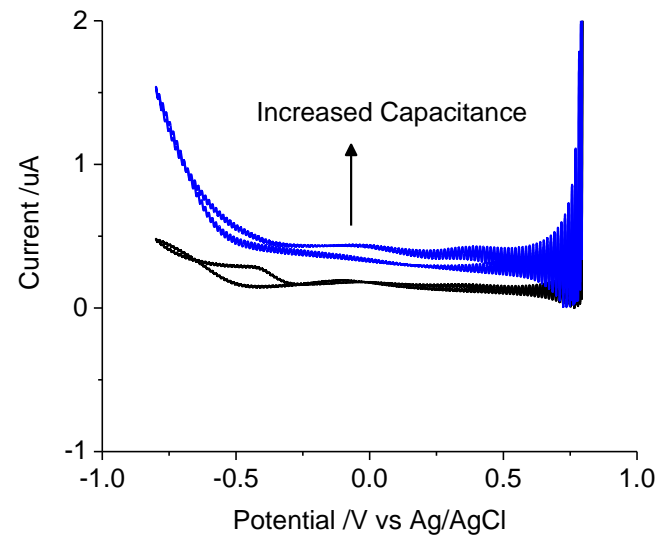

d

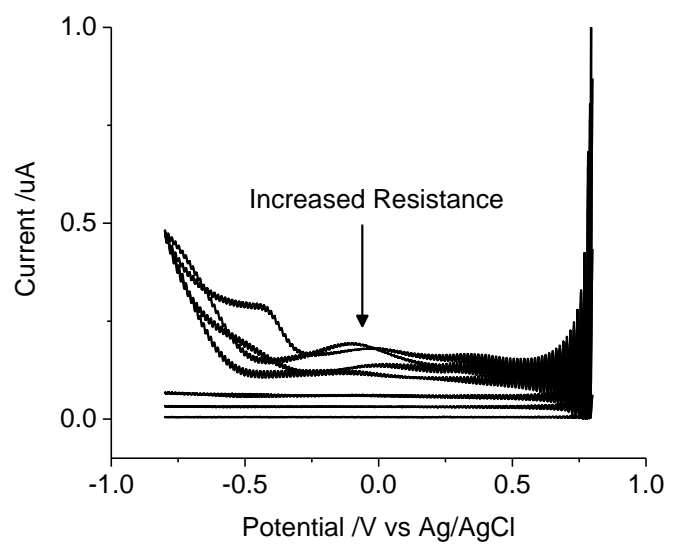

Figure 5 
a

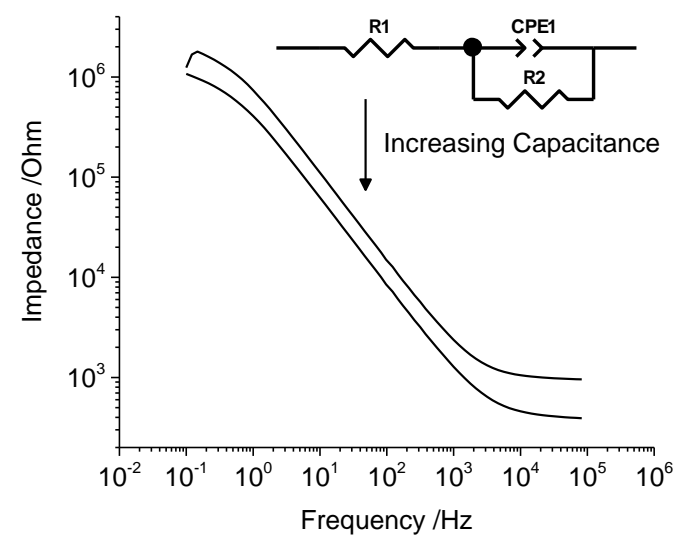

C

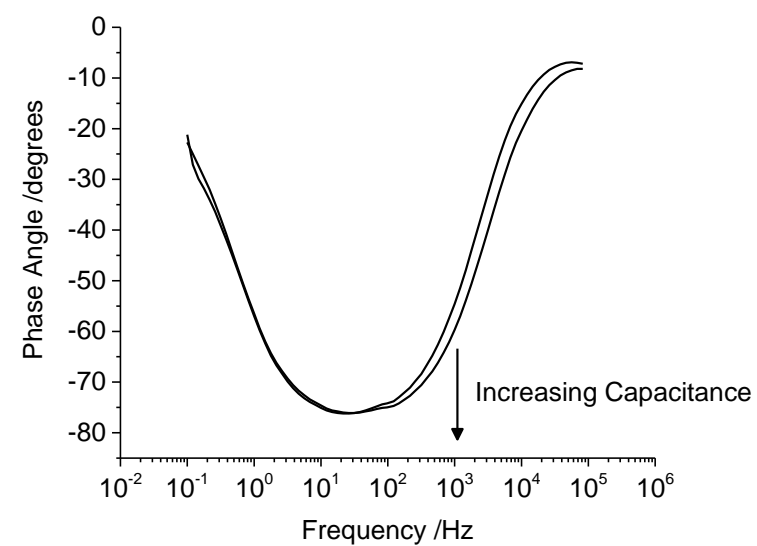

b

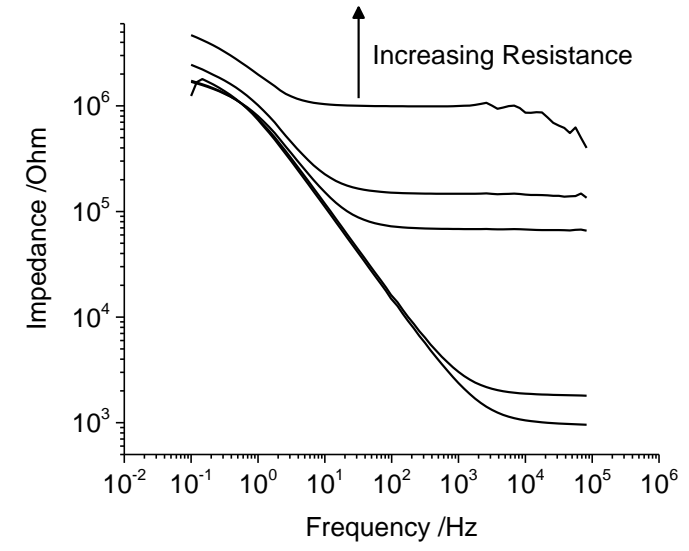

d

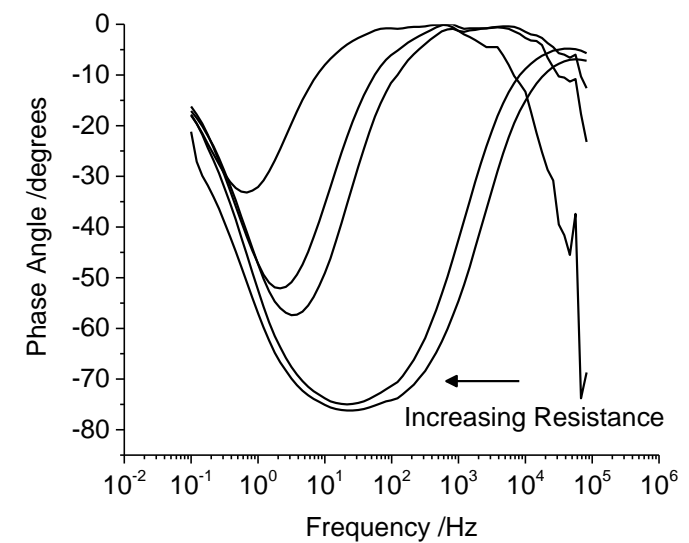

Figure 6 
a

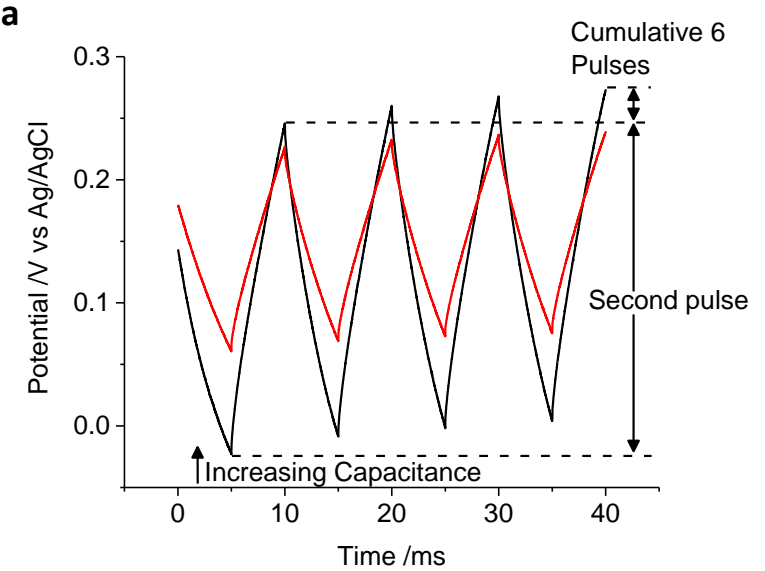

C

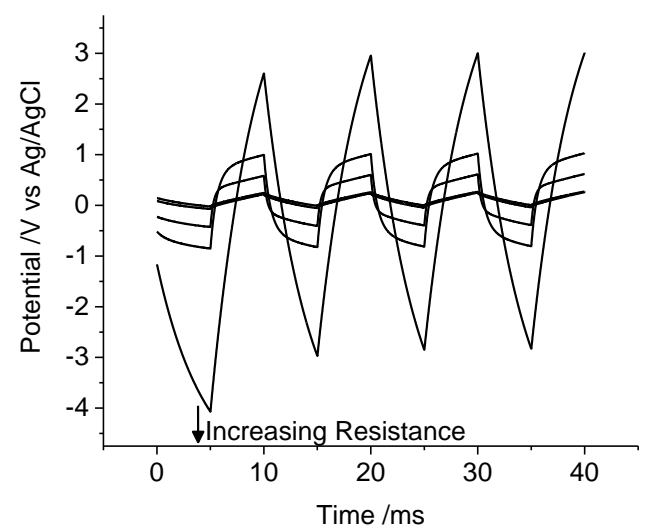

b

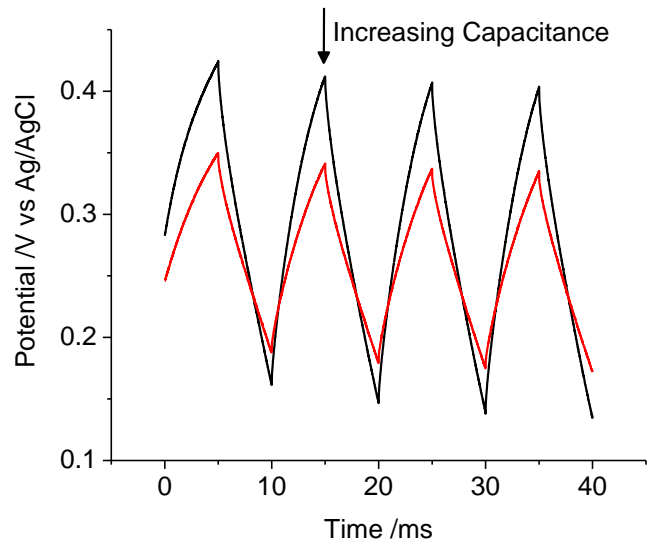

d

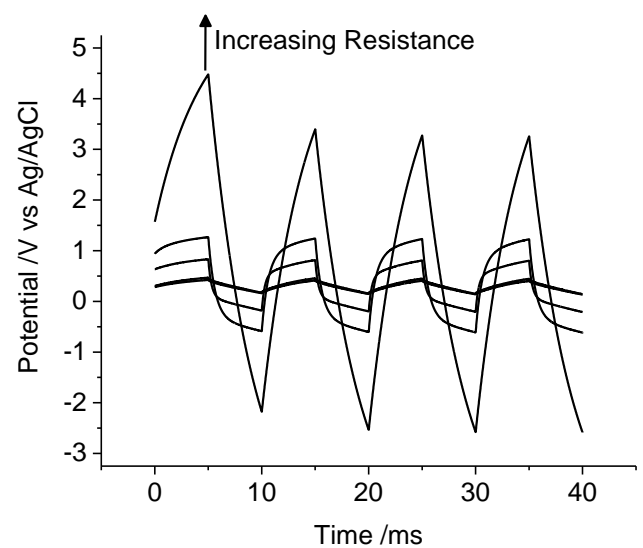

Figure 7 